\title{
Expression and localization of PDGF-B, PDGF-D, and PDGF receptor in the kidney of angiotensin II-infused rat
}

\author{
Nobukazu Ishizaka ${ }^{1}$, Gen Matsuzaki ${ }^{1}$, Kan Saito ${ }^{1}$, Eisei Noiri ${ }^{2}$, Ichiro Mori ${ }^{3}$ \\ and Ryozo Nagai ${ }^{1}$ \\ ${ }^{1}$ Department of Cardiovascular Medicine, University of Tokyo Graduate School of Medicine, Tokyo, Japan; \\ ${ }^{2}$ Department of Nephrology, University of Tokyo Graduate School of Medicine, Tokyo, Japan and \\ ${ }^{3}$ Department of Pathology, Wakayama Medical College, Tokyo, Japan
}

\begin{abstract}
Lipid accumulation in the kidney is a marker of tissue damage and may play a role in the development of renal injury. We have previously shown that long-term administration of angiotensin II in rats causes increased expression of transforming growth factor- $\beta 1$, coupled with an accumulation of lipids in the tubular and vascular wall cells in the kidney. In this study, we examine the regulation of expression of platelet-derived growth factor (PDGF) and its receptor system and their co-localization with lipid deposits in the kidneys of angiotensin IIinfused rats. Real-time RT-PCR showed that expression of PDGF-B, PDGF-D, and PDGF receptor- $\beta$ (PDGFR- $\beta$ ) mRNA was increased by angiotensin II infusion, and in situ hybridization showed the co-localization of these mRNAs. Tubular cells that had increased PDGF-B mRNA expression were positive for lipid deposition and also for cellular proliferation, which was indicated by the presence of proliferating cell nuclear antigen. By contrast, in the kidneys of angiotensin II-infused rats, apoptosis occurred in tubular cells that contained deposits of iron but not lipids. The deposition of lipids and upregulation of PDGF-B, PDGF-D, and PDGFR- $\beta$ induced by administration of angiotensin II were all suppressed by the selective angiotensin II type $1\left(\mathrm{AT}_{1}\right)$ receptor antagonist losartan, but not by the nonspecific vasodilator hydralazine. The findings that lipid accumulation, upregulation of PDGF-B, PDGF-D, and PDGFR- $\beta$, and cellular proliferation were topologically associated and regulated in an $\mathrm{AT}_{1}$ receptor-dependent manner in the kidney of angiotensin II-infused rats suggests that these phenomena are related.
\end{abstract}

Laboratory Investigation (2006) 86, 1285-1292. doi:10.1038/labinvest.3700486; published online 16 October 2006

Keywords: angiotensin II; hypertension; platelet-derived growth factor; lipid accumulation; apoptosis

Lipids may accumulate in nonadipose tissues such as the arterial wall, heart, and liver, in certain disease conditions, ${ }^{1-3}$ and the accumulated lipids may exacerbate morphological and functional damage in these tissues. ${ }^{2,4}$ Recent studies have shown that deposition of lipids occurs also in the kidney of the animal models of diabetes, obesity, and aging. ${ }^{5-8}$ Accumulation of triglycerides in the kidney is reported in animal models of unilateral ureteral obstruction, ${ }^{9}$ glycerol-induced rhabdomyolysis, and renal ischemia and subsequent reperfusion. ${ }^{10}$ The finding that increasing renal triglyceride content by transuding exogenous sterol regulatory elementbinding protein (SREBP)-1 resulted in upregulation

Correspondence: $\mathrm{Dr} \mathrm{N}$ Ishizaka, MD, PhD, Department of Cardiovascular Medicine, University of Tokyo Graduate School of Medicine, Hongo 7-3-1, Bunkyo-ku, Tokyo 113-8655, Japan. E-mail: nobuishizka-tky@umin.ac.jp

Received 2 May 2006; revised 4 September 2006; accepted 11 September 2006; published online 16 October 2006 of transforming growth factor (TGF)- $\beta 1$ and an increase in proteinuria, ${ }^{5}$ suggests that, besides being a marker of tissue damage, lipid accumulation in renal cells may be involved in the development of renal injury.

TGF- $\beta$ and platelet-derived growth factor $(\mathrm{PDGF})^{11}$ are thought to play key roles in renal damage in some disorders. ${ }^{11,12}$ Inhibition of angiotensin-converting enzyme activity and blockade of the angiotensin II type $1\left(\mathrm{AT}_{1}\right)$ receptor reduce the expression of these genes. ${ }^{13-17}$ whereas administration of angiotensin II upregulates their expression. ${ }^{18,19}$ Thus, activation of the renin-angiotensin system or increased local concentration of angiotensin II may enhance renal damage by the upregulation of these fibroproliferative genes in cortical tubular epithelial cells. ${ }^{20}$

We previously demonstrated that long-term administration of angiotensin II caused marked depositions of iron $^{21}$ and lipid ${ }^{22}$ in the rat kidney. Histological analysis showed that expression of 
TGF- $\beta$ and production of superoxides were both increased in renal cells with lipid deposition. We therefore hypothesized that expression of PDGF and its receptor system might be upregulated in the lipid-positive cells in the kidneys of angiotensin II-infused animals. In this paper, we investigate whether PDGF-B, PDGF-D, and PDGF receptor- $\beta$ (PDGFR- $\beta$ ) are induced in the kidneys of angiotensin II-infused rats, and determine the localization of the receptor and ligands by in situ hybridization.

\section{Materials and methods}

\section{Animal Models}

This study was performed in accordance with the guidelines for animal experimentation approved by the Animal Center for Biomedical Research, Faculty of Medicine, University of Tokyo. Angiotensin IIinduced hypertension was induced in male Sprague-Dawley rats $(250-300 \mathrm{~g})$ by subcutaneous implantation of an osmotic minipump (Alzet model 2001; Alza Pharmaceutical, Palo Alto, CA, USA) as described previously. ${ }^{23}$ In brief, $\mathrm{Val}^{5}$-Angiotensin II and norepinephrine (Sigma) were infused at doses of $0.7 \mathrm{mg} / \mathrm{kg} /$ day ( $\sim 140 \mathrm{ng} / \mathrm{min}$ ) and $2.8 \mathrm{mg} / \mathrm{kg} / \mathrm{day}$, respectively, for 7 days by subcutaneously implanted osmotic minipumps (Alza). These treatments exerted hypertensive effects (angiotensin II, $192 \pm 5 \mathrm{mmHg} \quad(n=12) ; \quad$ norepinephrine, $192 \pm 4$ $\mathrm{mmHg}(n=12), P<0.01$ vs control rats, $131 \pm 3 \mathrm{mmHg}$ $(n=6))$. Systolic blood pressure was measured in conscious rats by tail-cuff plethysmography (Ueda Seisakusyo). In some experiments, the selective $\mathrm{AT}_{1}$ receptor antagonist losartan $(25 \mathrm{mg} / \mathrm{kg} /$ day $)$ or the nonspecific vasodilator hydralazine $(15 \mathrm{mg} / \mathrm{kg} / \mathrm{day})$ (Sigma) were given in the drinking water, 2 days prior to pump implantation and throughout the angiotensin II infusion (angiotensin II + losartan, $126 \pm 5 \mathrm{mmHg}(n=7)$; angiotensin II + hydralazine $126 \pm 3 \mathrm{mmHg}(n=7))$.

\section{Real-Time Reverse Transcription-Polymerase Chain Reaction (RT-PCR)}

Quantitative RT-PCR was performed as described previously with LightCycler (Roche Diagnostics, Basel, Switzerland). ${ }^{24}$ Forward and reverse primers were $5^{\prime}$-CGGTGCAGGTGAGAAAGAT- $3^{\prime}$ and $5^{\prime}$ CCGAGTTTAGGTGTCTTG-3', respectively, for PDGF-B, 5'-TGTGCAGCCTAATGAGACT-3' and $5^{\prime}$ AGGAGATGGTGGAAGAAGTG-3', respectively, for PDGFR- $\beta$, and $5^{\prime}$-GAGGAGTTGAAGCTGACCA- ${ }^{\prime}$ and $5^{\prime}$-GTCCAGGCTCAAACTTCAGTA- $3^{\prime}$, respectively, for PDGF-D. Gene expression was normalized to the endogenous control, glyceraldehyde-3-phosphate dehydrogenase mRNA, and expression of the target gene expression in each sample was expressed relative to that in controls.

\section{Western Blot Analysis}

Western blot analysis for SREBP-1 was performed as described previously. ${ }^{22,25}$

\section{In Situ Hybridization and Immunohistochemistry}

cDNAs for in situ hybridization were obtained by RT-PCR. Forward and reverse primers were $5^{\prime}$ ATTCCTGAGGAACTCTATGAAAT- $3^{\prime}$ and $5^{\prime}$-AAGACT GGCTTCTTTCTCACAAT-3', respectively, for PDGF-B, $5^{\prime}$-GTCCTCAACATTTCGAGCACCTT-3' ${ }^{\prime}$ and $5^{\prime}$-CAG GCTGTAGACATAGTAAGTAT-3', respectively, for PDGFR- $\beta$, and $5^{\prime}$-ATCGGGACACTTTTGCGACT- ${ }^{\prime}$ and 5'-CAGATCTTCTACAGTATCGAAT-3', respectively, for PDGF-D. In situ hybridization was performed as described previously. ${ }^{26}$ Immunohistochemistry was performed as described previously. ${ }^{25}$ Primary antibodies against PDGFR- $\beta$ (Santa Cruz Biotechnology, Santa Cruz, CA, USA) and proliferating cell nuclear antigen (PCNA, DAKO Japan, Kyoto, Japan) were used at a dilution of 1/200.

\section{Deposition of Lipid and Iron}

Oil red O staining was performed on $3 \mu \mathrm{m}$ sections of unfixed, freshly frozen kidney samples. For semiquantification of the lipid deposition, images of each specimen stained with oil red $\mathrm{O}$ were taken with an Olympus BX51 microscope and a DP12 digital camera system (Olympus, Tokyo, Japan). Five images taken in the cortical regions of each sample were analyzed. The ratio of the areas of lipid deposition to the total tissue region area was calculated by using the image analysis software

Figure 1 Localization and regulation of PDGF-B, PDGFR- $\beta$, and PDGF-D mRNA expression. (a-p) Results of in situ hybridization. (a-d) Localization of PDGF-B mRNA. (a) Hybridization using the PDGF-B sense probe (background). (b-d) Hybridization using the PDGF-B antisense probe in angiotensin II (Ang II)-infused (b, d) and control (c) rats. (e-h) Localization of PDGFR- $\beta$ mRNA. (e) Hybridization using the sense probe (background). ( $\mathbf{f}-\mathbf{h})$ Hybridization using the PDGF-B antisense probe in Ang II-infused (f, h) and control (g) rats. (i-l) Localization of PDGF-D mRNA. (i) Hybridization using the PDGF-D sense probe (background). (j-l) Hybridization using the PDGF-D antisense probe in Ang II-infused $(\mathbf{j}, \mathbf{l})$ and control $(\mathbf{k})$ rats. $(\mathbf{m}-\mathbf{p})$ Co-localization of PDGF-B, PDGFR- $\beta$, and PDGF-D is examined. (m-n) and (o-p) are serially cut specimens. Specimens from Ang II-infused rats were stained with antisense probes that detect PDGF-B (m, o), PDGFR- $\beta$ (n), and PDGF-D (n). GM indicates glomerulus. Original magnifications, $\times 100(\mathbf{a}, \mathbf{b}, \mathbf{e}, \mathbf{f}, \mathbf{i}, \mathbf{j})$, and $\times 200(\mathbf{c}, \mathbf{d}, \mathbf{g}, \mathbf{h}, \mathbf{k}, \mathbf{l}-\mathbf{p})$. (q-s) Real-time RT-PCR. A summary of the results on PDGF-B (q), PDGFR- $\beta$ (r), and PDGF-D (s) mRNA are shown. Hyd, Los, and NE indicate hydralazine, losartan, and norepinephrine, respectively. Numbers of experiments in each group are given in parentheses. ${ }^{\star} P<0.01 \mathrm{vs}$ untreated control. 


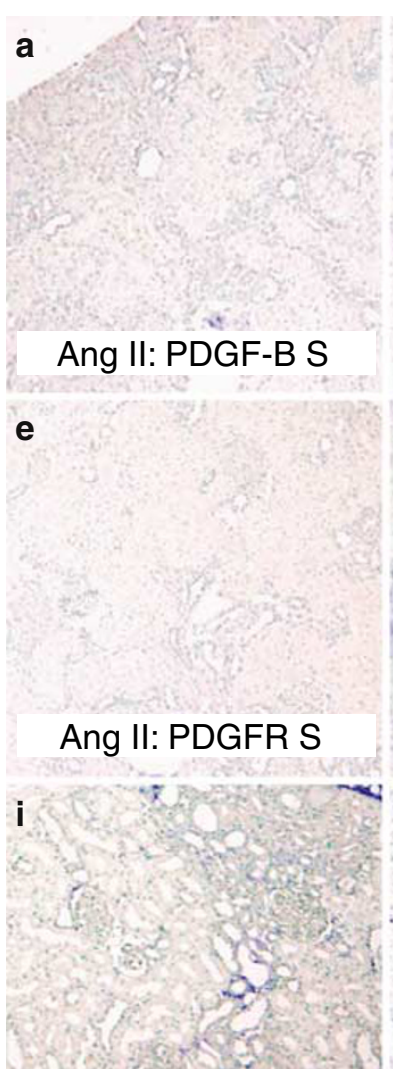

Ang II: PDGF-D S b

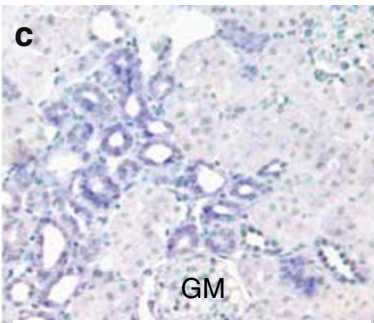

Ang II: PDGE-B AS d
GM

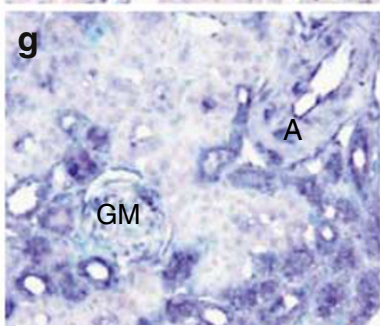

Ang II: PDGFR AS

Ang II: PDGFR AS

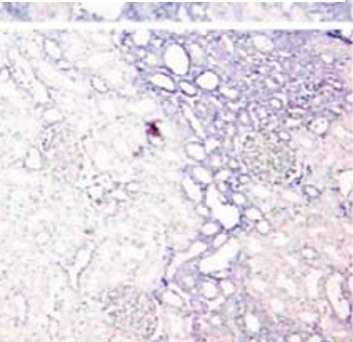

Ang II: PDGF-D AS
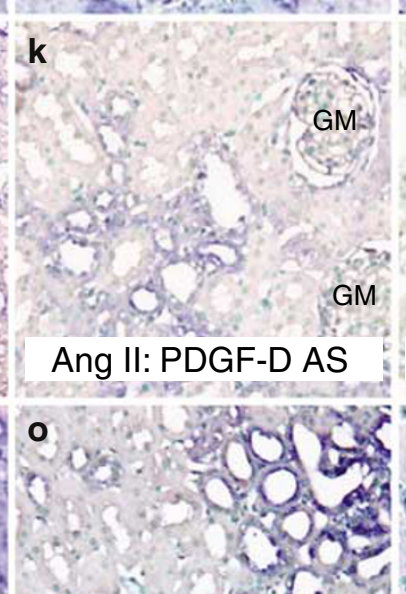

Control: PDGF-B AS

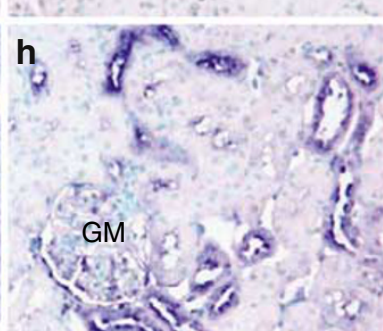

Control: PDGFR AS

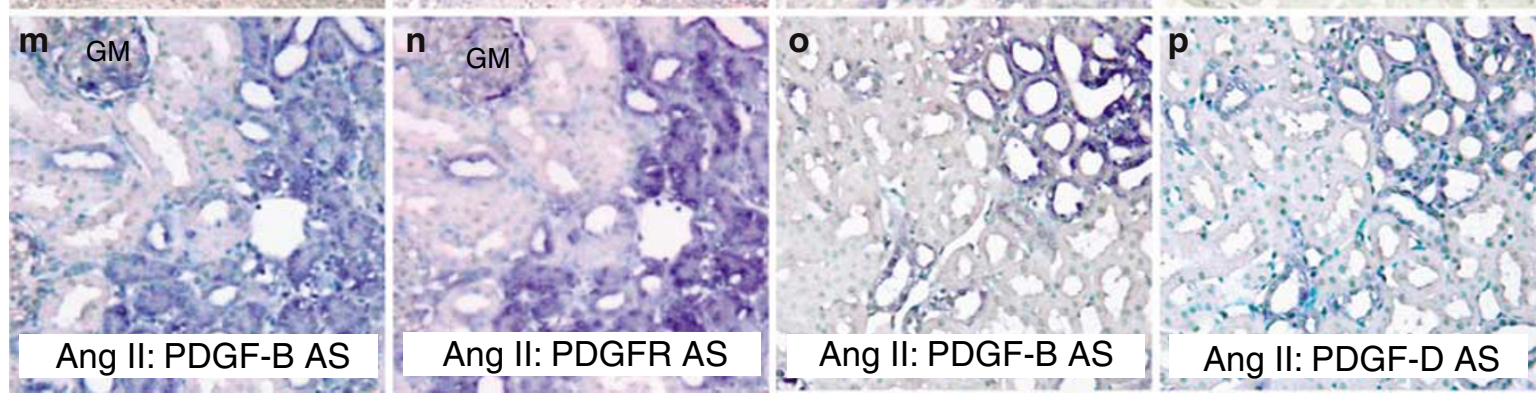

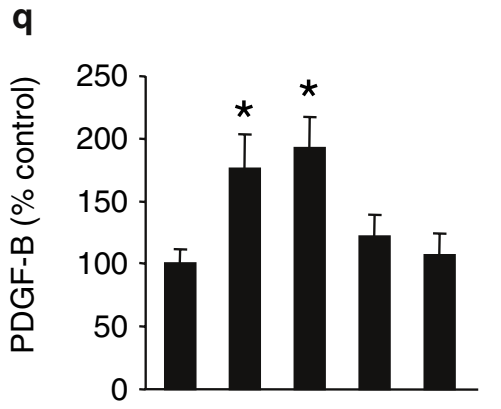

Ang II -+++

Hyd --+--

Los - - + -

$\mathrm{NE}-\quad-\quad-+$

$\begin{array}{llll}(10) & (6) & \text { (9) } & \text { (6) } \\ \text { (7) }\end{array}$
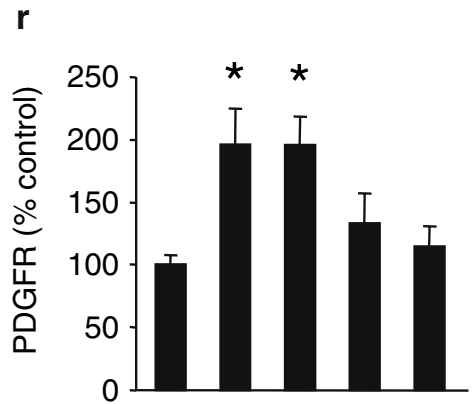

Ang $\mathrm{II}-+++-$

Hyd $-\quad+--$

LoS - - - + -

NE - $-\quad-\quad+$

(10) (6) (9) (6) (7)

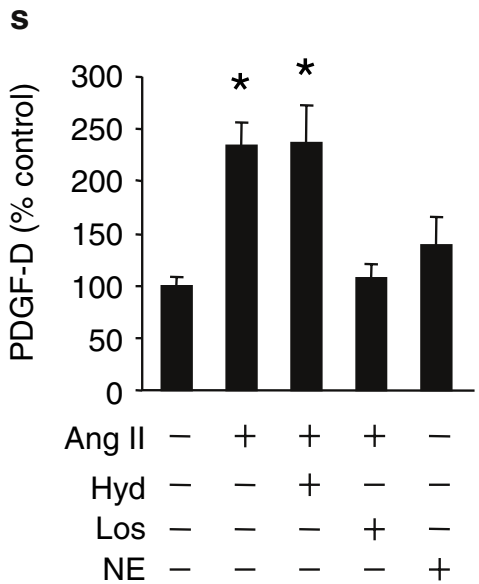

(6) (6) (6) (6) (6) 
Adobe Photoshop. Iron staining was performed by Prussian blue staining.

\section{Determination of Apoptosis}

Frozen sections ( $3 \mu \mathrm{m}$ thick) were fixed with in $4 \%$ paraformaldehyde and examined by the terminal deoxynucleotidyl transferase (TdT)-mediated dUTPbiotin nick end labeling (TUNEL) technique as described previously. ${ }^{27}$

\section{Statistical Analysis}

Data are expressed as the mean \pm s.e.m. We used ANOVA followed by a multiple comparison test to compare raw data, before expressing the results as a percentage of the control value using the statistical analysis software StatView version 5.0 (SAS Institute, NC, USA). A value of $P<0.05$ was considered to be statistically significant.

\section{Results}

\section{Expression and Localization of PDGF-B, PDGFR- $\beta$, and PDGF-D mRNA}

In situ hybridization revealed that the expression of PDGF-B mRNA was increased in the kidneys of angiotensin II-infused rats as compared to untreated controls (Figure 1a-d). Similarly, expression of PDGFR- $\beta$ mRNA (Figure 1e-h) and PDGF-D mRNA (Figure 1i-l) were increased after angiotensin II infusion. Staining of serially cut specimens revealed that the renal tubular cells, which showed increased levels of PDGF-B mRNA expression, also showed increased levels of PDGFR- $\beta$ mRNA (Figure 1m and $\mathrm{n}$ ) and PDGF-D mRNA (Figure 10 and $\mathrm{p}$ ). Quantitative RT-PCR showed that angiotensin II infusion significantly increased mRNA expression of PDGF-B, PDGFR- $\beta$, and PDGF-D, which could be suppressed by the $\mathrm{AT}_{1}$ receptor blockade by losartan, but not by the vasodilator hydralazine. Norepinephrine, which exerted hypertensive effects that were comparable to angiotensin II, did not increase the expression of mRNA in expression of either PDGF-B, PDGFR- $\beta$, or PDGF-D (Figure 1q-s).

\section{Localization of PDGF-B, Iron, and Lipid Deposits}

Staining of serially cut specimens showed that majority of tubular cells that expressed increased levels of PDGFR- $\beta$ and PDGF-B mRNA expression did not contain iron deposits (Figure 2a-c). Immunohistochemistry showed that levels of PDGFR- $\beta$ protein were higher after infusion of angiotensin II, but cells with increased PDGFR- $\beta$ protein expression were again found to be negative for iron deposition (Figure 2d-f). By contrast, staining of serial frozen sections showed that PDGF-B mRNA expression was intense in the tubular epithelial (Figure $2 \mathrm{~g}$ and $\mathrm{h}$ ) and vascular wall cells (Figure 2i and $\mathrm{j}$ ) that were positive for lipid deposits. PCNA was found to be positive in the tubular cells that expressed increased levels of PDGF-B mRNA (Figure $2 \mathrm{k}$ and $\mathrm{l}$ ) that was in accordance with previous report. ${ }^{28}$

By comparing four pairs of serially cut specimens of the kidneys of angiotensin II-infused rats, $84 \pm 6$ and $6 \pm 2 \%$ of the cells with increased PDGF-B

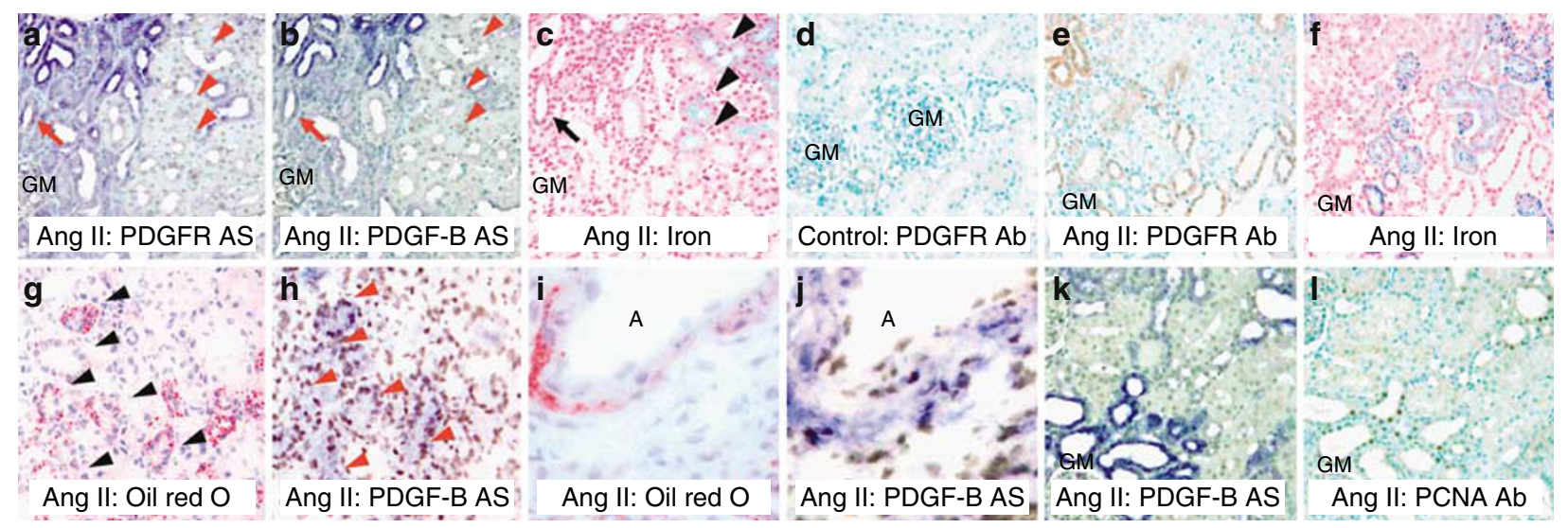

Figure 2 Localization of PDGF-B, PDGFR- $\beta$, iron, and lipids. (a-f, k, l) Formalin-fixed paraffin-embedded specimens. (g-j) Unfixed frozen specimens. (a, b, h, j, k) In situ hybridization. (c, f) Prussian blue staining. (d, e, l) Immunohistochemical staining for PDGFR- $\beta$ $(\mathbf{d}, \mathbf{e})$ and PCNA (l). (g, i) Oil red O staining. (a-c) Serial sections showing the localization of PDGFR- $\beta$ mRNA (a), PDGF-B mRNA (b), and iron (c). Cells positive for PDGF-B and PDGFR- $\beta$ mRNA expression did not co-localize with iron (arrowheads in a-c), with a few exceptions (arrows in a-c) F. Localization of PDGFR- $\beta$ protein and iron. Only very weak PDGFR- $\beta$ protein expression is observed in the control kidney (d). Serial sections show the localization of PDGFR- $\beta$ protein (e) and iron (f) in the kidney of angiotensin (Ang) II-infused rat. (g-j) Co-localization of lipid deposition and PDGF-B mRNA. Tubular cells that are positive for lipid deposition (g) are also positive for PDGF-B mRNA (h) in the kidney of Ang II-infused rat (arrowheads in $\mathbf{g}, \mathbf{h}$ ). Some vascular wall cells are also positive both for lipid deposition (i) and for PDGF-B mRNA (j). (k, l) Co-localization of PDGF-B mRNA (k) and PCNA-positivity (l) in the kidney of Ang II-infused rat. GM and A indicate glomerulus and intrarenal artery, respectively. Original magnifications, $\times 200(\mathbf{a}-\mathbf{h}, \mathbf{k}, \mathbf{l})$ and $\times 400(\mathbf{i}, \mathbf{j})$. 

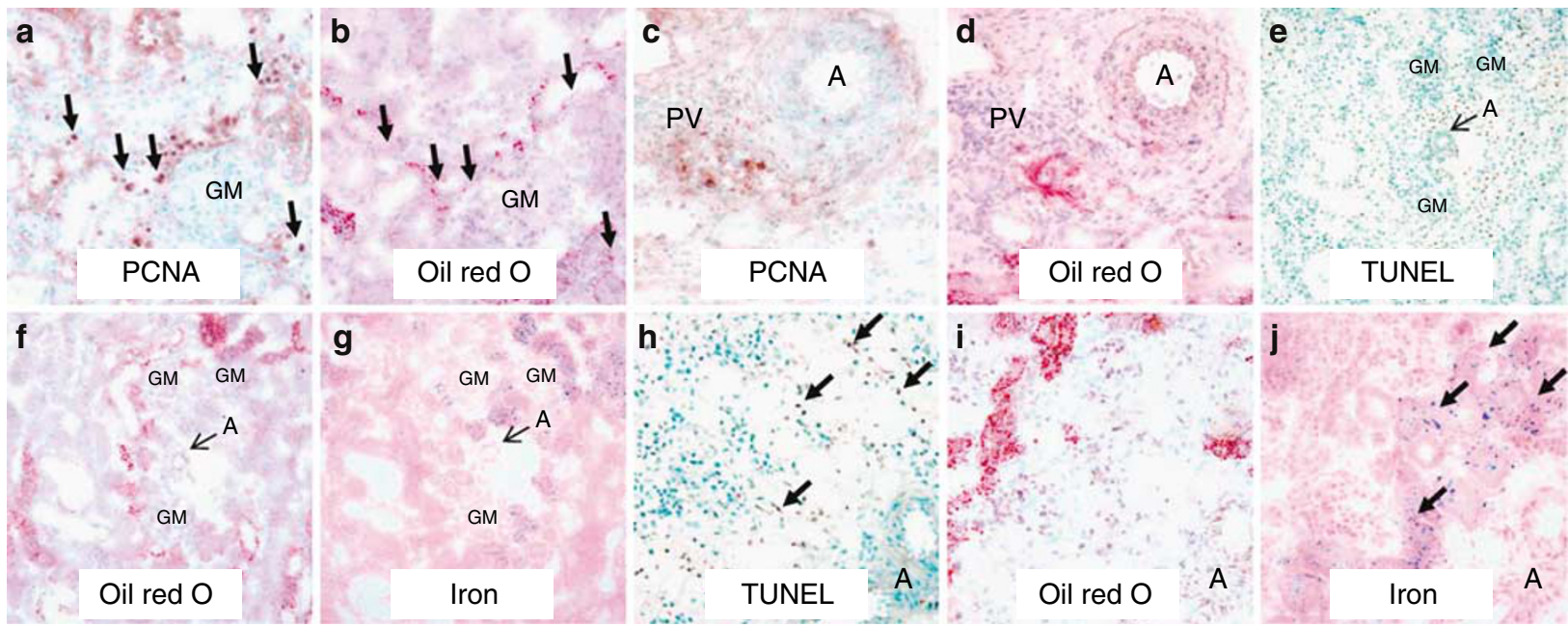

Figure 3 Lipid deposition and cellular proliferation and apoptosis. Unfixed frozen tissue specimens from the kidney of angiotensin (Ang) II-infused rats are used to demonstrate the co-localization, or non-co-localization, of cellular proliferation, apoptosis, lipid deposition, and iron deposition. (a, b) Staining of serial sections shows that tubular cells that are positive for PCNA (a, arrows) are also positive for oil red O staining (b, arrows). (c, d) Staining of serial sections shows that perivascular (PV) cells that are positive for PCNA (c) are also positive for oil red O staining (d). (e-g) Staining of serial sections shows that TUNEL-positive apoptotic cells (e) are negative for lipid staining (f), but positive for iron staining (g). (h-j) Higher magnification also shows the tubular cells that are positive for TUNEL staining (h, arrows) are negative for lipid deposition (i), whereas they are positive for iron staining (j, arrows). GM and A indicate glomerulus and intrarenal artery, respectively. Original magnification, $\times 200(\mathbf{a}-\mathbf{d}, \mathbf{h}-\mathbf{j})$ and $\times 100(\mathbf{e}-\mathbf{g})$.

mRNA expression were found to be positive for deposition of lipid and iron, respectively.

\section{Cellular Proliferation, Apoptosis, and Deposition of Lipids and Iron}

We then investigated whether PCNA-positive cells were also positive for accumulation of lipids. Tubular cells that were positive for PCNA staining were found to accumulate lipids (Figure 3a and b, arrows). Similarly, deposits of lipids were observed in the perivascular cells that were positive for PCNA (Figure 3c and d). By contrast, TUNELpositive tubular cells did not contain lipid deposits, but instead were positive for iron deposition (Figure $3 \mathrm{e}-\mathrm{j}$ ).

Effects of Various Pressor and Antipressor Agents on Lipid Deposition and Regulation of Expression of Lipid Metabolism-Related Genes

We next determined the effects of the pressor and antipressor agents, which had been used to investigate the regulation of PDGF-B, PDGF-D, and PDGFR- $\beta$ (Figure 1) on angiotensin II-induced accumulation of lipids and upregulation lipid metabolism-related genes. Angiotensin II-induced lipid accumulation could be suppressed by losartan, but not by hydralazine (Figure $4 \mathrm{a}-\mathrm{d}$ ). Administration of norepinephrine did not result in lipid deposition in the kidney (Figure 4e). The ratio of the areas of lipid deposition to the total tissue region area in each group were as follows $(n=4$ in each group): control, $0.1 \pm 0.0 \%$; angiotensin II,
$6.1 \pm 0.9 \% \quad(P<0.01$ vs control $)$; angiotensin $\mathrm{II}+$ hydralazine, $5.0 \pm 1.4 \%(P<0.01$ vs control $)$; angiotensin II + losartan, $0.3 \pm 0.3 \%$ (NS vs control); and norepinephrine, $0.3 \pm 0.2 \%$ (NS vs control).

The angiotensin II-induced upregulation of protein expression of SREBP-1 (Figure $4 \mathrm{f}$ and $\mathrm{g}$ ) was inhibited by losartan, but not by hydralazine. Angiotensin II-induced upregulation of mRNA expression of FAS and LDL-R were also suppressed by losartan, but not by hydralazine (Figure $4 \mathrm{~h}$ and i). Norepinephrine treatment did not increase expression of SREBP-1 (data not shown), FAS, or LDL-R (Figure $4 \mathrm{~h}$ and i). Expression of HMG-CoA-R was not significantly altered by any of these treatments (Figure 4J).

\section{Discussion}

In the present study, we demonstrated that expression of PDGF-B, PDGF-D, and PDGFR- $\beta$ mRNA was increased in the kidney of rats that were made hypertensive by angiotensin II but not by norepinephrine. In situ hybridization showed the colocalization of mRNA expression of these genes. Histological analysis showed that only a small fraction of PDGF-B mRNA signals co-localized with iron deposits, but a substantial fraction co-localized with lipid droplets. In the kidney of angiotensin IIinfused rat, cells with increased PDGF-B mRNA expression and in those with lipid accumulation were also PCNA positive. These data collectively suggest that lipid deposition, PDGF, and renal cell proliferation may be related in the kidney of the angiotensin II-induced hypertensive rat. 


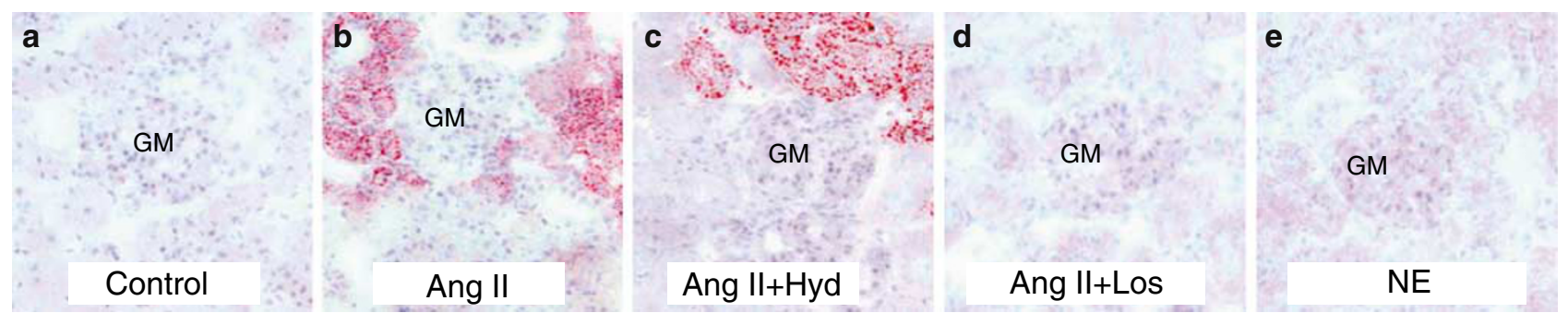

f

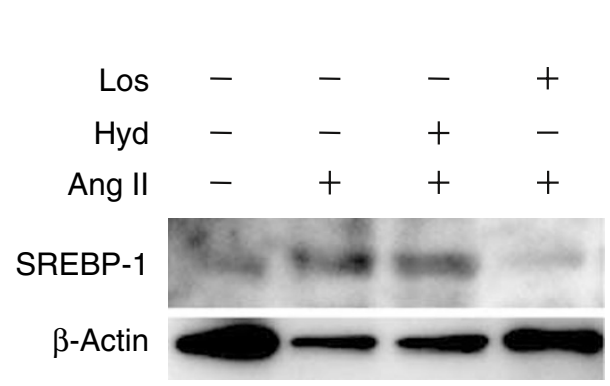

g

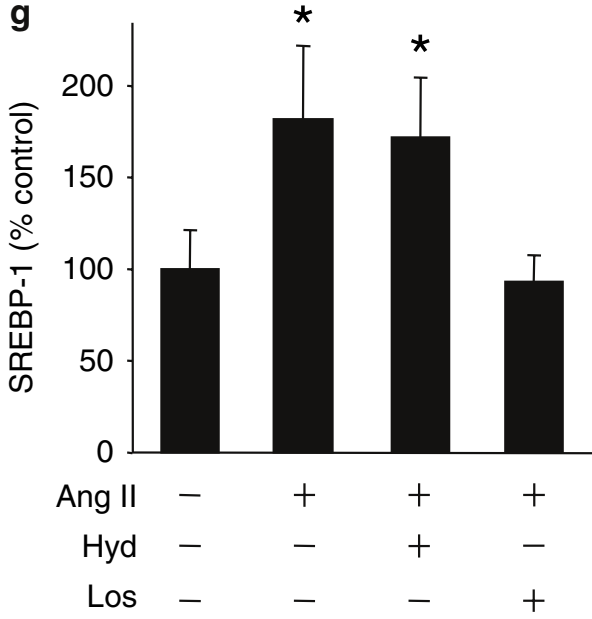

h

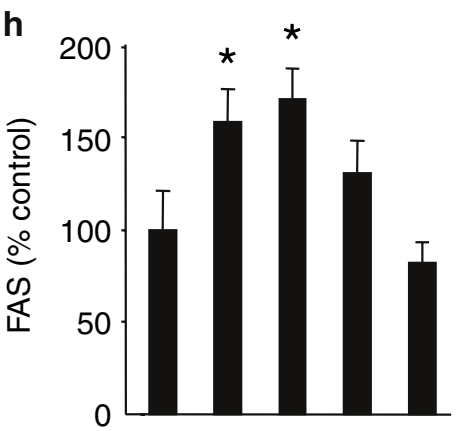

Ang II -+++

Hyd - - + - -

LOS - - - + -

$\mathrm{NE}-\quad-\quad-\quad+$
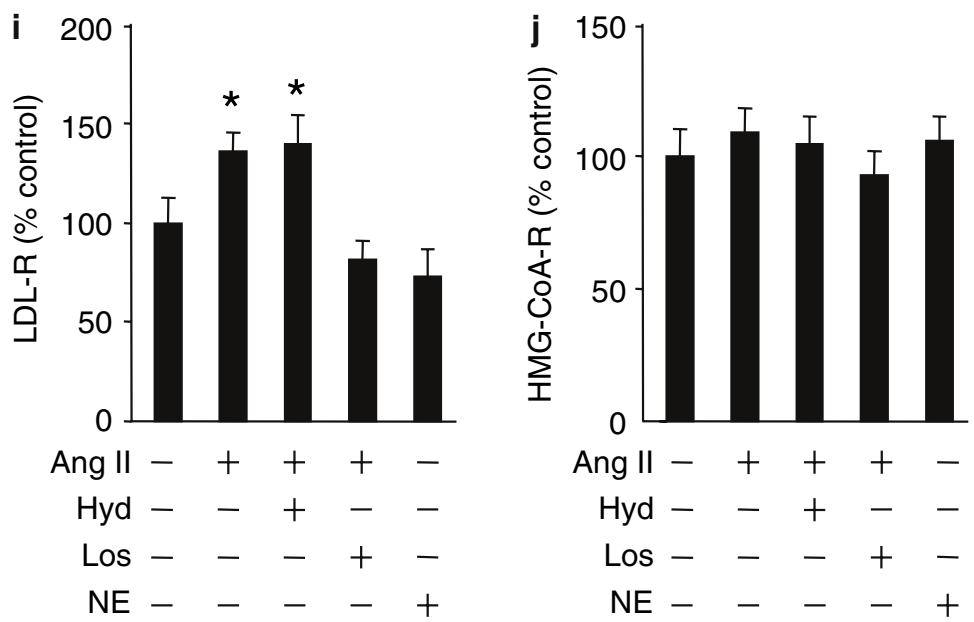

Figure 4 Effects of pressor and antipressor agents on lipid deposition, protein expression of SREBP-1, and mRNA expression of FAS, LDL receptor, and HMG CoA reductase. (a-e) Oil red $\mathrm{O}$ staining of the sections from untreated rats (a), rats treated with angiotensin (Ang) II (b), Ang II plus hydralazine (Hyd) (c), Ang II plus losartan (Los) (d), and norepinephrine (NE) (e). Original magnification, $\times 200$. (f, g) Protein expression of SREBP-1. Representative Western blot analysis (f) and summary of data ( $n=5-7$ in each group) (g). (h-j) Summary of data of real-time RT-PCR ( $N=6$ in each group) for the expression of fatty acid synthase (FAS) (h), LDL receptor (LDL-R) (i), and HMG-CoA reductase (HMG-CoA-R) (j) mRNA. * $P<0.05$ vs untreated control.

It has been previously shown by Johnson et $a 1^{19}$ that administration of angiotensin II induces PDGF-B expression in the renal tubular cells. In the present study, we showed that angiotensin II infusion induced upregulation of PDGF-B and PDGFR- $\beta$ mRNA in the kidney, and this could be suppressed by the $\mathrm{AT}_{1}$ receptor antagonist losartan, but not by the vasodilator hydralazine. These findings suggest that angiotensin II-upregulated expression of these genes by an $\mathrm{AT}_{1}$ receptordependent mechanism, an idea that is further supported by our finding that norepinephrine did not cause upregulation of these genes.

We also demonstrated that mRNA expression of PDGF-D, a newly discovered member of PDGF family that mediates renal cell proliferation, also showed similar pattern of regulation by pressor and antipressor agents. The distribution pattern of 
PDGF-D mRNA was reported to be closely similar to that of PDGFR- $\beta$ in murine renal fibrosis induced by unilateral ureteral obstruction. ${ }^{29}$ In the current study, we showed the co-localization of mRNA expression of PDGF-D, PDGF-B, and PDGFR- $\beta$ (Figure $1 \mathrm{~m}-\mathrm{p}$ ) in the kidney of the angiotensin IIinduced rat.

We previously found that long-term administration of angiotensin II resulted in a marked deposition of iron ${ }^{21}$ and lipid ${ }^{22}$ in the kidney. Although several previous studies have shown deposition of iron ${ }^{30}$ and lipid ${ }^{5,6,8,31}$ in other animal models, the physiological importance of the renal iron and lipid deposition has not been well established. Sun et a ${ }^{5}$ have recently reported that introducing exogenous SREBP-1 gene to the kidney resulted not only in the renal lipid deposition, but also in increased albuminuria and upregulation of TGF- $\beta 1$ expression, suggesting that alterations in lipid metabolism in the kidney may have a role in renal function and regulation of gene expression. We also found the topological association between TGF- $\beta 1$ mRNA expression and lipid deposition, but not iron deposition, in the kidney of angiotensin II-infused rat. ${ }^{18,22}$ As both PDGF and TGF- $\beta$ may to play a modulatory role in the progression of renal injury in certain diseased condition, ${ }^{32}$ these previous findings lead us to investigate the regulation of PDGF-B, as well as PDGF-D and PGDFR- $\beta$, and their histological localization in the kidney of angiotensin II-infused rats.

In a previous study, we showed that angiotensin II infusion induced renal cellular proliferation, which could be suppressed by losartan, but not hydralazine. ${ }^{27}$ In the current study, in addition to the topological association between PDGF-B, PCNA, and lipid deposition, mRNA expression of PDGFB/PDGF-D (Figure 1q and s) and area of lipid deposition (Figure 4a-e) were regulated by an $\mathrm{AT}_{1}$ receptor-dependent and pressor-independent manner. As PDGF-D, as well as PDGF-B, may promote renal cellular proliferation when upregulated, ${ }^{33}$ these finding might suggest that altered lipid homeostasis is an upstream phenomenon in the PDGF-B/ PDGF-D-induced renal cellular proliferation in the kidneys of angiotensin II-treated rats. This scenario is supported by the finding by a previous in vitro study that showed that simulation of the renal cells with triglyceride-rich lipoproteins increased the secretion of PDGF and TGF- $\beta$ from these cells and promote their proliferation. ${ }^{34}$ In contrast to proliferation, TUNEL-positive apoptosis was found in the cells with iron deposition, but not in those with lipid deposition. Previous studies showed that heme or iron may exacerbate renal cell apoptosis, presumably, in part, by iron-induced oxidative stress. ${ }^{35,36}$ Again, a causal or resultant relationship between iron deposition and renal cell apoptosis could not be determined in the current study; it will be pursued in future studies.

Accumulation of lipid droplets in glomerular and renal tubular cells has been reported in an animal model of diabetes, ${ }^{5,8}$ which is postulated to modulate the expression of fibrogenesis-related genes and proteinuria. ${ }^{5}$ Importantly, analysis of renal biopsy specimens from patients with kidney diseases showed that deposition of lipid, ${ }^{37}$ as well as iron, ${ }^{38}$ may not be uncommon. The pathophysiological roles of lipid deposition in the kidney and its possible association with the renin-angiotensin system need further investigation.

In conclusion, long-term administration of angiotensin II increased the expression of PDGF-B, PDGF$\mathrm{D}$, and PDGFR- $\beta$ mRNA in the rat kidney. It was shown histologically that cells with increased PDGF-B mRNA expression contained lipid deposits. In addition, cellular proliferation was observed in lipid-positive cells and PDGF-B-positive cells. These data collectively suggest the possible relationship between altered lipid metabolism, upregulation of PDGF-B/PDGF-D, and cellular proliferation in the kidney of hypertensive animal models of angiotensin II infusion.

\section{Acknowledgements}

This work was supported by Grants in Aid for Scientific Research from the Ministry of Education, Science, and Culture of Japan (Grant 13671098). We are highly appreciative of Kyoko Furuta and Naoko Amitani for their excellent technical assistance.

\section{References}

1 Kita T, Nagano Y, Yokode M, et al. Probucol prevents the progression of atherosclerosis in Watanabe heritable hyperlipidemic rabbit, an animal model for familial hypercholesterolemia. Proc Natl Acad Sci USA 1987;84:5928-5931.

2 Sharma S, Adrogue JV, Golfman L, et al. Intramyocardial lipid accumulation in the failing human heart resembles the lipotoxic rat heart. FASEB J 2004;18: 1692-1700.

3 Farrell GC, Larter CZ. Nonalcoholic fatty liver disease: from steatosis to cirrhosis. Hepatology 2006;43: S99-S112.

4 Ohara Y, Peterson TE, Harrison DG. Hypercholesterolemia increases endothelial superoxide anion production. J Clin Invest 1993;91:2546-2551.

5 Sun L, Halaihel N, Zhang W, et al. Role of sterol regulatory element-binding protein 1 in regulation of renal lipid metabolism and glomerulosclerosis in diabetes mellitus. J Biol Chem 2002;277:18919-18927.

6 Jiang T, Liebman SE, Lucia MS, et al. Role of altered renal lipid metabolism and the sterol regulatory element binding proteins in the pathogenesis of agerelated renal disease. Kidney Int 2005;68:2608-2620.

7 Jiang T, Wang Z, Proctor G, et al. Diet-induced obesity in $\mathrm{C} 57 \mathrm{BL} / 6 \mathrm{~J}$ mice causes increased renal lipid accumulation and glomerulosclerosis via a sterol regulatory element-binding protein-1c-dependent pathway. J Biol Chem 2005;280:32317-32325.

8 Wang Z, Jiang T, Li J, et al. Regulation of renal lipid metabolism, lipid accumulation, and glomerulosclero- 
sis in FVBdb/db mice with type 2 diabetes. Diabetes 2005;54:2328-2335.

9 Tannenbaum J, Purkerson ML, Klahr S. Effect of unilateral ureteral obstruction on metabolism of renal lipids in the rat. Am J Physiol 1983;245:F254-F262.

10 Zager RA, Johnson AC, Hanson SY. Renal tubular triglyercide accumulation following endotoxic, toxic, and ischemic injury. Kidney Int 2005;67:111-121.

11 Tang WW, Ulich TR, Lacey DL, et al. Platelet-derived growth factor-BB induces renal tubulointerstitial myofibroblast formation and tubulointerstitial fibrosis. Am J Pathol 1996;148:1169-1180.

12 Desmouliere A, Geinoz A, Gabbiani F, et al. Transforming growth factor-beta 1 induces alpha-smooth muscle actin expression in granulation tissue myofibroblasts and in quiescent and growing cultured fibroblasts. J Cell Biol 1993;122:103-111.

13 Junaid A, Rosenberg ME, Hostetter TH. Interaction of angiotensin II and TGF-beta 1 in the rat remnant kidney. J Am Soc Nephrol 1997;8:1732-1738.

14 Toblli JE, DeRosa G, Cao G, et al. ACE inhibitor and angiotensin type I receptor antagonist in combination reduce renal damage in obese Zucker rats. Kidney Int 2004;65:2343-2359.

15 Guo G, Morrissey J, McCracken R, et al. Contributions of angiotensin II and tumor necrosis factor-alpha to the development of renal fibrosis. Am J Physiol Renal Physiol 2001;280:F777-F785.

16 Boffa JJ, Lu Y, Placier S, et al. Regression of renal vascular and glomerular fibrosis: role of angiotensin II receptor antagonism and matrix metalloproteinases. J Am Soc Nephrol 2003;14:1132-1144.

17 Szabo A, Lutz J, Schleimer K, et al. Effect of angiotensin-converting enzyme inhibition on growth factor mRNA in chronic renal allograft rejection in the rat. Kidney Int 2000;57:982-991.

18 Saito K, Ishizaka N, Aizawa T, et al. Role of aberrant iron homeostasis in the upregulation of transforming growth factor-beta1 in the kidney of angiotensin IIinduced hypertensive rats. Hypertens Res 2004;27: 599-607.

19 Johnson RJ, Alpers CE, Yoshimura A, et al. Renal injury from angiotensin II-mediated hypertension. Hypertension 1992;19:464-474.

20 Mezzano SA, Aros CA, Droguett A, et al. Renal angiotensin II up-regulation and myofibroblast activation in human membranous nephropathy. Kidney Int Suppl 2003;86:S39-S45.

21 Ishizaka N, Aizawa T, Yamazaki I, et al. Abnormal iron deposition in renal cells in the rat with chronic angiotensin II administration. Lab Invest 2002;82: 87-96.

22 Saito K, Ishizaka N, Hara M, et al. Lipid accumulation and transforming growth factor-beta upregulation in the kidneys of rats administered angiotensin II. Hypertension 2005;46:1180-1185.

23 Ishizaka $\mathrm{N}$, de Leon $\mathrm{H}$, Laursen JB, et al. Angiotensin II-induced hypertension increases heme oxygenase-1 expression in rat aorta. Circulation 1997;96:19231929.

24 Ishizaka N, Saito K, Mori I, et al. Iron chelation suppresses ferritin upregulation and attenuates vascular dysfunction in the aorta of angiotensin II-infused rats. Arterioscler Thromb Vasc Biol 2005;25:2282-2288.

25 Aizawa T, Ishizaka N, Taguchi J, et al. Heme oxygenase-1 is upregulated in the kidney of angiotensin IIinduced hypertensive rats: possible role in renoprotection. Hypertension 2000;35:800-806.

26 Saito K, Ishizaka N, Aizawa $\mathrm{T}$, et al. Iron chelation and a free radical scavenger suppress angiotensin IIinduced upregulation of TGF-beta1 in the heart. Am J Physiol Heart Circ Physiol 2005;288:H1836-H1843.

27 Aizawa T, Ishizaka N, Usui S, et al. Angiotensin II and catecholamines increase plasma levels of 8-epi-prostaglandin F(2alpha) with different pressor dependencies in rats. Hypertension 2002;39:149-154.

28 Nakagawa T, Sasahara M, Haneda M, et al. Role of PDGF B-chain and PDGF receptors in rat tubular regeneration after acute injury. Am J Pathol 1999;155: 1689-1699.

29 Taneda S, Hudkins KL, Topouzis S, et al. Obstructive uropathy in mice and humans: potential role for PDGF-D in the progression of tubulointerstitial injury. J Am Soc Nephrol 2003;14:2544-2555.

30 Izuhara Y, Nangaku M, Inagi R, et al. Renoprotective properties of angiotensin receptor blockers beyond blood pressure lowering. J Am Soc Nephrol 2005;16: 3631-3641.

31 Yoneyama $\mathrm{T}$, Ohkawa $\mathrm{S}$, Watanabe $\mathrm{T}$, et al. The contribution of nitric oxide to renal vascular wall thickening in rats with L-NAME-induced hypertension. Virchows Arch 1998;433:549-557.

32 Lipkowitz MS, Klotman ME, Bruggeman LA, et al. Molecular therapy for renal diseases. Am J Kidney Dis 1996;28:475-492.

33 Hudkins KL, Gilbertson DG, Carling M, et al. Exogenous PDGF-D is a potent mesangial cell mitogen and causes a severe mesangial proliferative glomerulopathy. J Am Soc Nephrol 2004;15:286-298.

34 Nishida Y, Oda H, Yorioka N. Effect of lipoproteins on mesangial cell proliferation. Kidney Int Suppl 1999;71:S51-S53.

35 Kawabata T, Ma Y, Yamador I, et al. Iron-induced apoptosis in mouse renal proximal tubules after an injection of a renal carcinogen, iron-nitrilotriacetate. Carcinogenesis 1997;18:1389-1394.

36 Gonzalez-Michaca L, Farrugia G, Croatt AJ, et al. Heme: a determinant of life and death in renal tubular epithelial cells. Am J Physiol Renal Physiol 2004; 286:F370-F377.

37 Lee HS, Lee JS, Koh HI, et al. Intraglomerular lipid deposition in routine biopsies. Clin Nephrol 1991;36: 67-75.

38 Wang $\mathrm{H}$, Nishiya $\mathrm{K}$, Ito $\mathrm{H}$, et al. Iron deposition in renal biopsy specimens from patients with kidney diseases. Am J Kidney Dis 2001;38:1038-1044. 